\title{
Differential proteomics analysis of the analgesic effect of electroacupuncture intervention in the hippocampus following neuropathic pain in rats
}

\author{
Yong-Hui Gao, Shu-Ping Chen, Jun-Ying Wang, Li-Na Qiao, Fan-Ying Meng, Qiu-Ling Xu and Jun-Ling Liu*
}

\begin{abstract}
Background: Evidence is building steadily on the effectiveness of acupuncture therapy in pain relief and repeated acupuncture-induced pain relief is accompanied by improvement of hippocampal neural synaptic plasticity. To further test the cellular and molecular changes underlying analgesic effect of acupuncture, the global change of acupuncture associated protein profiles in the hippocampus under neuropathic pain condition was profiled.

Methods: The chronic constrictive injury $(\mathrm{CCl})$ model was established by ligature of the unilateral sciatic nerve in adult Wistar rats. Rats were randomized into normal control (NC) group, CCl group, and CCl with electroacupuncture (EA) stimulation group. EA was applied to bilateral Zusanli (ST36) and Yanglingquan (GB34) in the EA group. Differentially expressed proteins in the hippocampus in the three groups were identified by two-dimensional gel electrophoresis and matrix-assisted laser desorption/ionization time of flight mass spectrometry. The functional clustering of the identified proteins was analyzed by Mascot software.

Results: After $\mathrm{CCl}$, the thermal pain threshold of the affected hind footpad was decreased and was reversed gradually by 12 sessions of acupuncture treatment. Following EA, there were 19 hippocampal proteins identified with significant changes in expression (>2-fold), which are involved in metabolic, physiological, and cellular processes. The top three canonical pathways identified were "cysteine metabolism", "valine, leucine, and isoleucine degradation" and "mitogen-activated protein kinase (MAPK) signaling".
\end{abstract}

Conclusions: These data suggest that the analgesic effect of EA is mediated by regulation of hippocampal proteins related to amino acid metabolism and activation of the MAPK signaling pathway.

Keywords: Acupuncture analgesia, Cumulative effect, Hippocampus, Chronic constrictive injury

\section{Background}

Low back pain, including sciatica, is a common symptom that causes severe psychological and economical problems [1-3]. It is well established that acupuncture therapy is effective in relieving symptoms of patients with neuropathic pain [4-6]. Experimental studies have also demonstrated that acupuncture intervention can effectively relieve chronic neuropathic and inflammatory pain in rats $[7,8]$. Hence, acupuncture therapy is considered a better choice for pain relief due to the limited options, side effects, and insufficient analgesia of currently available drugs.

\footnotetext{
* Correspondence: junling_liu@yahoo.cn

Department of Physiology, Institute of Acupuncture and Moxibustion, China Academy of Chinese Medical Sciences, Beijing 100700, China
}

The mechanism underlying acupuncture analgesia is believed to relate to induction of functional responses in various brain regions. Animal studies have identified a number of mesencephalic and brainstem nuclei putatively involved in mediating acupuncture information [9-11]. Interestingly, fMRI studies [12-14] showed that acupuncture stimulation resulted in activation or deactivation of multiple limbic areas including the hippocampal complex. We previously reported that repeated acupuncture intervention-induced pain relief in rats with chronic constrictive injury (CCI) of the sciatic nerve was accompanied by improvement of hippocampal neural synaptic plasticity and regulation of CaMKII and synaptophysin expression [15].

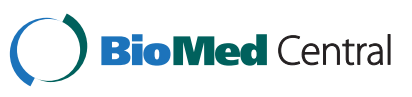


Numerous studies have demonstrated a close association between the hippocampal activity and neuropathic pain [16-19]. Alterations in the morphology and gene expression in the hippocampus have been detected under different pain conditions [20]. Correspondingly, multiple proteins or peptides [20-23], including galanin, rat spinal cord expression protein 1, and NF-kappa B, were reported to play key roles in neuropathic pain. However, at present there are limited protein network data linking the hippocampus to the acupuncture analgesic effect. Furthermore, as the cellular and molecular changes underlying cumulative acupuncture analgesia are very complicated, identification of new proteins involved in this process will help elucidate the underlying mechanism of acupuncture analgesia.

In the present study, we examined the global changes of acupuncture intervention-associated proteins in the hippocampus and identified the protein function clusters and potential signaling pathways in CCI rats. The use of two-dimensional gel electrophoresis (2-DE) and matrixassisted laser desorption/ionization time of flight mass spectrometry (MALDI-TOF MS) approach enabled us to perform an unbiased and comprehensive analysis of protein expression changes [24].

\section{Methods}

\section{Animals}

A total of 60 female Wistar rats (240-300 g) were obtained from the Experimental Animal Center of the Peking Union Medical College (Beijing) and housed within the animal care facilities in the Institute of Acupuncture and Moxibustion, China Academy of Chinese Medical Sciences. Animals were randomized into normal control (NC) (sham ligature), CCI model, and CCI with electroacupuncture (EA) stimulation groups ( $n=20$ per group). Ten animals in each group were used for protein extraction and 10 for RNA extraction. All experimental procedures were approved by the Institute of Acupuncture and Moxibustion of China Academy of Chinese Medical Sciences and were identical to the "Guidelines for Laboratory Animal Care and Use" of the Chinese Ministry of Science and Technology (2006).

\section{$\mathrm{CCl}$ Pain model and pain threshold detection}

The CCI model was established by ligating the unilateral sciatic nerve, as previously reported $[25,26]$. Briefly, under anesthesia (25\% urethane plus $2 \times 1.5 \%$ chloralose, $0.4 \mathrm{~mL} / 100 \mathrm{~g}$ body weight) and routine sterilization, the left sciatic nerve was exposed at the mid-thigh level by blunt dissection through the biceps femoris. Four constrictive ligatures (4-0 non-absorbable suture) were tied around the nerve at the distal end close to the bifurcation site at approximately $1 \mathrm{~mm}$ spacing. The ligature was alright until a moderate muscular contraction of the leg could be seen. For the NC group, the rats underwent the same procedure but without nerve ligature.

Five days after CCI, and every three days after CCI, the withdrawal latency (PWL; i.e., thermal pain threshold) of the bilateral hind paws was determined using a 37370 Algesia Detector (Ugo, Italy). The radiant heat source was focused on the plantar surface of a hindpaw, and a light intensity was preset to obtain a baseline latency of approximately $15 \mathrm{~s}$. A cut-off time was set at $20 \mathrm{~s}$ to avoid tissue damage. Each rat underwent two trials with a 5 min interval, and the mean value of two trials was used as the withdrawal latency. To minimize differences in individual animals, the difference value of PWL (PWLD) between the healthy and the affected side was calculated.

\section{Electroacupuncture}

According to the theory of traditional Chinese medicine, Zusanli (ST36) and Yanglingquan (GB34) (Figure 1A) are considered the most effective acupoints and are commonly used for treating low back pain in China and other countries $[27,28]$. In the present study, the animals in the EA group were treated with EA stimulation of bilateral ST36 and GB34 from the 7th day on after CCI. The acupoints were punctured with stainless steel filiform needles (diameter $0.35 \mathrm{~mm}$, length $40 \mathrm{~mm}$, Huatuo; Suzhou Medical Appliance Manufactory, Jiangsu, China) to a depth of approximately $2-3 \mathrm{~mm}$, and stimulated electrically for 30 min using a Han's EA Stimulator (LH202; Neuroscience Research Center, Peking University, Beijing, China). The stimulating intensity and frequency of EA were $1 \mathrm{~mA}$ and $2 / 15 \mathrm{~Hz}$, respectively. During EA stimulation, the animals were awake and constrained with a special cloth bag. The treatment was administered once daily continuously for 12 consecutive days.

\section{Protein extraction}

After termination of the EA treatment on the $19^{\text {th }}$ day after CCI, all rats in the three groups were deeply anesthetized and killed by decapitation. The hippocampal tissue was removed rapidly on an ice plate, washed with normal saline, and then suspended in ultrasound lysis buffer. The tissue was sonicated for $5 \mathrm{~min}$ on ice using a Sonifier750 (Branson Ultrasonics Co., Danbury, CT, USA). After adding $5 \mathrm{mg}$ of RNase and 100 units of RQ1 DNase (Promega, Madison, WI, USA), the tissue lysate was incubated at room temperature for $1 \mathrm{~h}$ to fully dissolve the protein, and then centrifuged $(45,000 \mathrm{r} / \mathrm{min})$ for $1 \mathrm{~h}$. The supernatant was collected for determining the protein concentration with a Plusone 2-D Quant Kit (Amersham Pharmacia Biotech, Uppsala, Sweden). After qualification of proteins by Bradford method, the supernatants were aliquoted and stored at $-80^{\circ} \mathrm{C}$ until electrophoresis. 

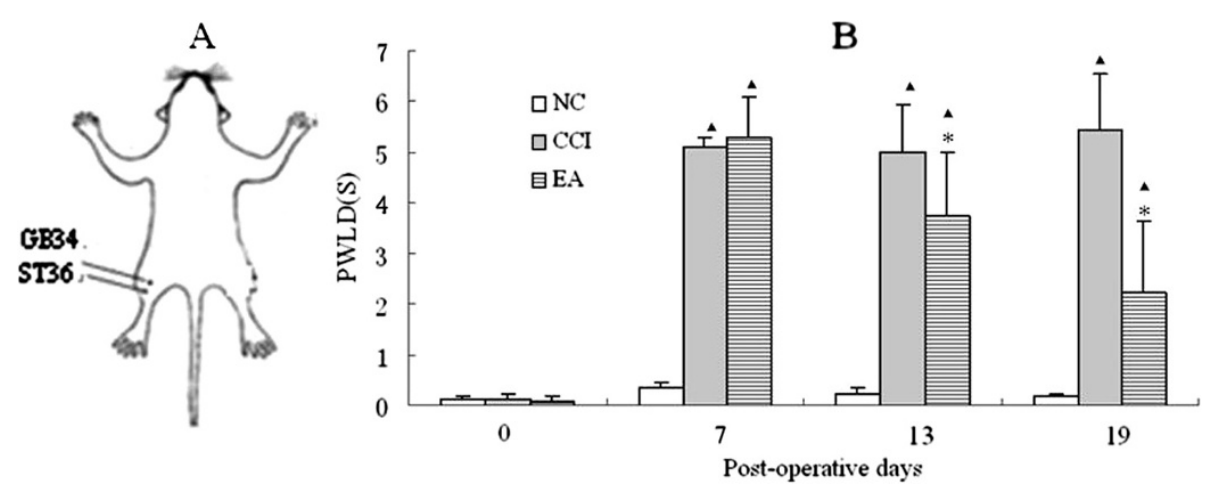

Figure 1 Schematic locations of the acupoints in rats and effects of EA on pain threshold (A) Schematic locations of the acupoints in rats, (B) Effects of EA on PWLD in rats of the NC, CCI and EA groups $(\mathbf{n}=\mathbf{2 0}$ per group). PWLD was recorded before $C C l$, and on day 7,13 and 19 after CCl. Data are presented as mean \pm SD. $\mathbf{\Delta} P<0.05$, compared with the NC group; ${ }^{*} P<0.05$, compared with the CCl group.

\section{2-DE}

The first-dimensional iso-electric focusing (IEF) electrophoresis was performed on pre-cast, dry $24 \mathrm{~cm}$ immobilized $\mathrm{pH}$ gradient strips $(\mathrm{pH} 3-10)$, and on a Bio- $\mathrm{Rad}$ Isoelectric Focusing System (Bio-Rad, Hercules, CA, USA). Each strip was first hydrated for $2 \mathrm{~h}$ with the protein in $300 \mu \mathrm{L}$ of IEF hydration buffer (7 M urea, $2 \mathrm{M}$ thiourea, 4\% CHAPS, $0.5 \%$ carrier ampholyte, $40 \mathrm{mM}$ DTT, and $0.002 \%$ bromophenol blue). IEF was performed using the following condition: $30 \mathrm{~V}$ for $10 \mathrm{~h}$, $200 \mathrm{~V}$ for $1 \mathrm{~h}, 500 \mathrm{~V}$ for $1 \mathrm{~h}, 1000 \mathrm{~V}$ for $1 \mathrm{~h}$, and $8000 \mathrm{~V}$ for $13 \mathrm{~h}$ until IPG strips were removed from the first dimension. The strips were then subjected to a two-step equilibration using equilibration buffer I [6 $\mathrm{M}$ urea, $2 \%$ (m/V) SDS, $0.375 \mathrm{M}$ Tris- $\mathrm{HCl} \mathrm{pH}$ (8.8), 30\% (V/V) glycerol, and 1\% DTT], followed by equilibration buffer II [6 M urea, 2\% SDS, $0.375 \mathrm{M}$ Tris-HCl (pH 8.8), 20\% glycerol, and $135 \mathrm{mM}$ iodoacetamide] for $15 \mathrm{~min}$ respectively just before 2-DE. The second dimension of vertical separation was then performed for approximately $4 \mathrm{~h}$ on $12.5 \%$ SDS-PAGE at $30 \mathrm{~mA} /$ gel. Silver staining of the gels was performed using a silver stain kit (Amersham Pharmacia Biotech).

\section{Image analysis}

The gels were scanned at a resolution of 400 dpi with an Amersham ImageScanner 2D (Amersham Pharmacia Biotech). ImageMaster 2D Platinum 5.0 software was used for spot detection, gel alignment, spot quantification, and log normalized data, followed by calculation of the protein molecular weight (MW) of proteins in synchronizing electrophoresis and the isoelectric point (pI) over the $\mathrm{pH}$ range of the IEF gel strips. Images from the three groups were compared. Proteins that had significant differences between the CCI and EA groups were shown in this study. Based on the gel-to-gel variation of reduced error for highly abundant proteins, protein spots that showed at least 2-fold difference [29] in the average spot relative volume between two groups at $95 \%$ confidence level ( $\mathrm{t}$-test; $p<0.05$ ) were selected as significantly different. For subsequent mass spectrometry analysis, significant spot coordinates were transferred to a Coomassie stained preparative gel for spot picking.

\section{Enzymatic digestion of protein spots and mass spectrometry for protein identification}

In-gel protein digestion was performed as described previously [30,31]. The digested products were treated with $0.5 \% \mathrm{TFA} / 30 \% \mathrm{ACN}$ solution $(25 \mu \mathrm{L})$ for $30 \mathrm{~min}$. Peptide mass fingerprinting (PMF) analysis was then performed in a Bruker Reflex ${ }^{\mathrm{TM}}$ III MALDI-TOF mass spectrometer (Bruker Daltonik GmnH, Germany) for identification of proteins.

\section{Protein identification}

The monoisotopic peptide masses obtained from MALDITOF MS were interpreted utilizing Mascot freeware (www.matrixscience.com). Monoisotopic masses were used to search the Rattus databases, allowing a peptide mass accuracy of $150 \mathrm{ppm}$ and one partial cleavage. Two modifications of oxidation of methionine and carbamidomethyl of cysteine were considered. For the unambiguous identified proteins, more than five peptides must be matched, and the sequence coverage must be greater than $15 \%$. The reference descriptions of the searched differential proteins from MASCOT searching were input into online MAS3.0 software (http://bioinfo.capitalbio.com/ mas3/analysis/create) to perform function, networks, and canonical pathway analyses.

\section{Confirmation of differential proteins by quantitative real- time PCR}

After termination of the EA treatment, all rats were deeply anesthetized and killed as above. The hippocampus tissue 
was removed rapidly on an ice plate and total RNA was extracted using Trizol (Invitrogen, Carlsbad, CA, USA). RNA was reverse transcribed with oligo (dT) and M-MLV reverse transcriptase (Promega, Madison, WI, USA). Primers were designed using Primer 3.0 and synthesized by Sangon (Shanghai, China). Reactions were performed in triplicate using $10 \mathrm{ng}$ of $\mathrm{cDNA}$ in a $25 \mu \mathrm{L}$ reaction that contained $1 \mu \mathrm{L}$ of each amplification primer $(5 \mu \mathrm{L})$ and $12.5 \mu \mathrm{L}$ of real-time PCR Master Mix (Applied Biosystems, Carlsbad, California, USA). Samples were amplified using standard cycling condition, and data were collected and analyzed with SDS 2.3 software. Relative mRNA expression levels were measured. Each assay was evaluated by a comparative method validated by Applied Biosystems with the formula $2^{-\Delta \Delta}$ ct.

\section{Confirmation of differential proteins by Western blot analysis}

Total protein $(30-50 \mu \mathrm{g})$ was loaded onto $10 \%$ SDSPAGE gels and transferred onto PVDF membranes (Millipore, Billerica, MA, USA) for Western blot. Primary antibodies and dilutions used were: monoclonal MBP antibody (1:200; Millipore), rabbit polyclonal GOT1 antibody (1:200; Novus Biologicals, Littleton, CO, USA), rabbit polyclonal PITPNA antibody (1:500; ProteinTech Group, Chicago, IL, USA), and monoclonal $\beta$-actin antibody (1:5000; Millipore). Tissue protein levels were determined by immunoblot of tissue lysates after SDS-PAGE, and were transferred to PVDF membranes. Reactive bands were visualized using the ECL plus Western blotting detection system (Amersham Pharmacia Biotech) after incubating membranes with HRP-linked IgG (Amersham Pharmacia Biotech).

\section{Statistical analysis}

PWLD of the paws of the rats and quantitative real-time PCR data as well as Western blotting data are expressed as mean $\pm \mathrm{SD}$, and were analyzed by one-way ANOVA. The least significant difference (LSD) test was performed to compare the differences between every two groups. All $P$ values were 2 -sided, and $P<0.05$ was considered significant.

\section{Results}

\section{Effects of EA on pain threshold}

Before ligature of the sciatic nerve, there was no difference in the PWLD between the healthy and the affected hindlimbs in the NC, CCI, and EA groups $(P>0.05)$, suggesting a similar baseline thermal pain threshold in rats in the three groups (Figure 1B). After CCI surgery, the rats showed typical neuropathic behavior reactions, and a significant reduction in the PWL on the side of nerve ligature $(P<0.01)$. The PWLD was increased considerably in both the CCI and EA groups in comparison with the NC group $(P<0.05)$. There were no differences in pain threshold before EA treatment between the CCI and EA groups. With increasing number of EA treatment sessions, there was a gradual decrease in PWLD, with a significant decrease in PWLD in the EA group by 12 treatment sessions compared with the CCI group $(P<0.05)$ (Figure 1B), suggesting an apparent analgesic effect of repeated EA interventions.

\section{Effects of EA on expression of the differentially expressed proteins}

The overview 2-DE silver staining profile from the hippocampus showed that the pI's of almost all proteins were located between 3 and 10, and there were highly reproducible patterns between the groups (Figure 2). Approximately 800 spots were detected on the ImageMaster 2D Platinum. After matching the maps from the same groups, the average intensities (10 maps per group) of each spot were calculated and compared between the groups. Following 12 sessions of EA, 19 proteins exhibited a differential change in the averaged intensity compared with the CCI group, and were returned to the NC group levels (Figure 3). Of these proteins, 11 were upregulated and 8 down-regulated after $\mathrm{CCI}$ alone.

\section{Identification of differentially expressed proteins in the hippocampus}

All the 19 proteins were positively identified in our MS analyses (Table 1). These proteins contributed to over 20 functional clusters (Figure 4), and were comprised of proteins involved in biological processes (46.99\%), molecular function (36.14\%), and cellular components (16.87\%). Kyoto Encyclopedia of Genes and Genomes (KEGG) and genMAPP analysis showed that these proteins were involved in over 60 networks and over 30 pathways (Figure 5). The top-ranked canonical pathways were related to "cysteine metabolism", "valine, leucine and isoleucine degradation", and "mitogen-activated protein kinase (MAPK) signaling".

\section{Validation of differentially expressed proteins by real-time PCR and Western blot analysis}

To verify the reliability of the proteomics analysis, three hippocampal differential proteins, phosphatidylinositol transfer protein alpha (PITPNA), cytoplasmic aspartate aminotransferase (GOT1), and myelin basic protein $(M B P)$, were selected as representative proteins and subjected to quantitative real-time PCR and Western blot analysis (Figure 6). The mRNA levels of PITPNA were significantly up-regulated after $\mathrm{CCI}$ in comparison with the NC group $(\mathrm{P}<0.05)$, while there was no change in GOT1 mRNA expression in the CCI group $(P>0.05)$. Following EA intervention, PITPNA and GOT1 mRNA expression levels were significantly down-regulated in 


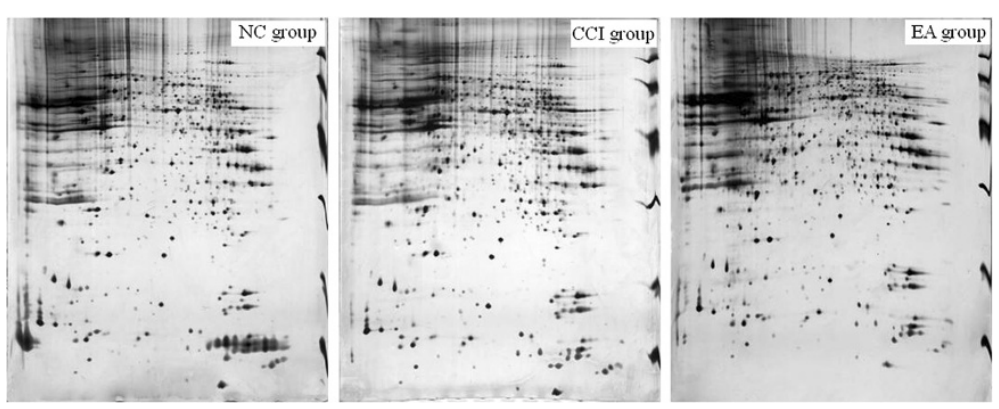

Figure 2 Hippocampal tissue protein profiles obtained with silver stained gels from the three groups.

the EA group compared to the CCI group $(P<0.05)$. The expression of $M B P$ mRNA in the NC group was comparable to that in CCI group $(P>0.05)$, but was significantly up-regulated in the EA group $(P<0.05)$. The results from Western blot analysis were similar to those from 2-DE.

\section{Discussion}

In the present study, we demonstrated that in CCIinduced neuropathic pain rats, 12 sessions of EA could effectively suppress CCI-induced pain reactions. This result is identical to those reported in our previous studies [26,32]. We also compared global changes of acupuncture-associated proteins in the hippocampus under CCI condition, and found 19 differential expressed proteins that returned to the normal control levels following repeated EA interventions. These differential proteins are involved in physiological, metabolic, and cellular processes, with major pathways including "cysteine metabolism", "valine, leucine and isoleucine degradation", and "MAPK signaling".

There is strong evidence that treatment of sciatica patients using thermal acupuncture can result in a progressive increase in the pain threshold with increasing number of treatment sessions, and an accompanying gradual improvement in symptoms [33]. In this study, we found that stress-induced-phosphoprotein 1 (STIP1), which participates in short-term memory formation and

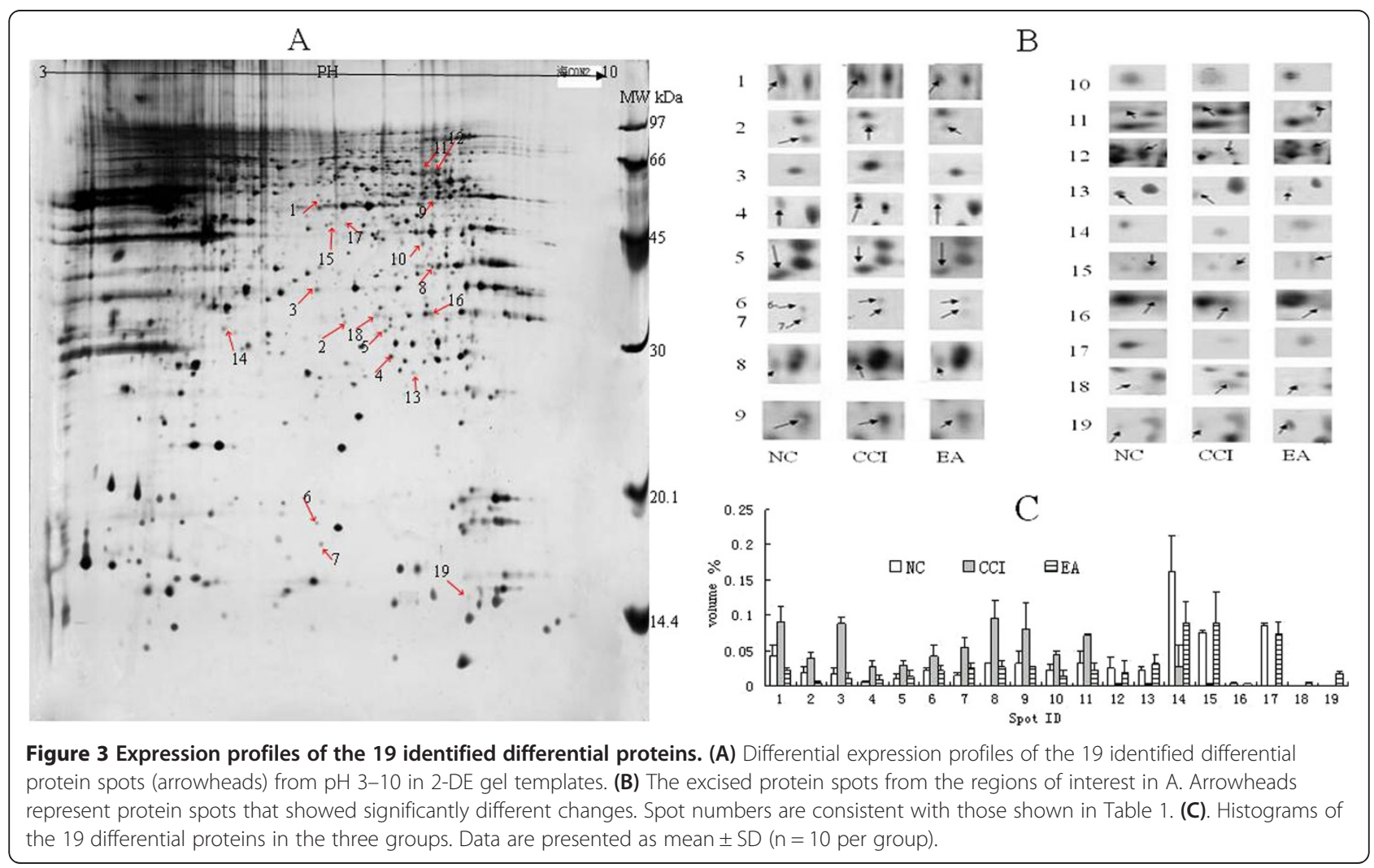


Table 1 List of hippocampal differentially expressed proteins after EA

\begin{tabular}{|c|c|c|c|c|c|c|c|c|c|c|c|}
\hline $\begin{array}{l}\text { Spot } \\
\text { ID }\end{array}$ & $\begin{array}{c}\text { DB } \\
\text { accession }\end{array}$ & Protein name & $\begin{array}{l}\mathrm{NCBI} G \mathrm{GI} \\
\text { identifier }\end{array}$ & $\begin{array}{l}\text { Ratio } \\
\mathrm{CCl} / \mathrm{NC}\end{array}$ & $\begin{array}{l}\text { Ratio EA/ } \\
\text { CCI }\end{array}$ & $\begin{array}{l}\text { Ratio } \\
\text { EA/NC }\end{array}$ & Score & $\begin{array}{c}\text { Protein } \\
\text { pl }\end{array}$ & $\begin{array}{l}\text { Protein } \\
\text { MW }\end{array}$ & $\begin{array}{c}\text { Sequence } \\
\text { coverage }(\%)\end{array}$ & $\begin{array}{l}\text { Number of mass values } \\
\text { matched }\end{array}$ \\
\hline 1 & PDIA3 & protein disulfide isomerase family $\mathrm{A}$, member 3 & gi|8393322 & 2.12 & 0.25 & 0.54 & 261 & 5.88 & 57010 & 51 & 28 \\
\hline 2 & PURA & purine-rich element binding protein $A$ & gi|293343021 & 2.13 & 0.14 & 0.30 & 167 & 6.07 & 35157 & 51 & 13 \\
\hline 3 & SIRT2 & sirtuin 2 & gi|149056443 & 4.78 & 0.13 & 0.64 & 137 & 5.37 & 43763 & 44 & 16 \\
\hline 4 & PITPNA & phosphatidylinositol transfer protein, alpha & gi|8393962 & 4.65 & 0.34 & 1.60 & 144 & 5.97 & 32119 & 61 & 22 \\
\hline 5 & MPST & mercaptopyruvate sulfurtransferase & gi|20304123 & 2.48 & 0.47 & 1.16 & 105 & 5.88 & 33205 & 36 & 11 \\
\hline 6 & STMN1 & stathmin 1 & gi|8393696 & 2.00 & 0.50 & 1.01 & 79 & 5.76 & 17278 & 34 & 6 \\
\hline 7 & NME1 & non-metastatic cells 1 & gi|19924089 & 3.49 & 0.47 & 1.63 & 121 & 5.96 & 17296 & 58 & 8 \\
\hline 8 & NDUFA1 & NADH dehydrogenase (ubiquinone) 1 alpha & gi|170295834 & 2.93 & 0.28 & 0.81 & 110 & 7.64 & 40753 & 44 & 15 \\
\hline 9 & $A L D H 2$ & aldehyde dehydrogenase 2 family & gi|45737866 & 2.51 & 0.34 & 0.87 & 117 & 6.69 & 56079 & 39 & 20 \\
\hline 10 & IVD & isovaleryl-CoA dehydrogenase & gi|6981112 & 2.01 & 0.32 & 0.64 & 148 & 8.03 & 46862 & 44 & 18 \\
\hline 11 & STIP1 & stress-induced-phosphoprotein 1 & gi|20302113 & 2.14 & 0.33 & 0.71 & 167 & 6.40 & 63158 & 39 & 19 \\
\hline 12 & HNRNPL & heterogeneous nuclear ribonucleoprotein $\mathrm{L}$ & gi|197245939 & 0.11 & 7.29 & 0.77 & 140 & 6.70 & 62572 & 40 & 18 \\
\hline 13 & GSTO1 & glutathione S-transferase omega 1 & gi|12585231 & 0.11 & 13.72 & 1.49 & 78 & 6.25 & 27936 & 43 & 9 \\
\hline 14 & GNB1 & $\begin{array}{l}\text { guanine nucleotide binding protein (G protein), } \\
\text { beta polypeptide } 1\end{array}$ & gi|71089935 & 0.17 & 3.35 & 0.56 & 74 & 4.80 & 28609 & 39 & 16 \\
\hline 15 & GOT1 & aspartate aminotransferase 1 & gi|122065118 & 0.04 & 28.61 & 1.18 & 166 & 6.73 & 46628 & 36 & 15 \\
\hline 16 & HIBADH & 3-hydroxyisobutyrate dehydrogenase & gi|83977457 & 0.28 & 3.81 & 1.07 & 64 & 8.73 & 35679 & 24 & 7 \\
\hline 17 & $\angle D H B$ & lactate dehydrogenase B & gi|6981146 & 0.23 & 3.73 & 0.87 & 94 & 5.70 & 36874 & 44 & 21 \\
\hline 18 & MAPKK1 & mitogen-activated protein kinase kinase 1 & gi|266566 & 0.34 & 4.53 & 1.56 & 89 & 5.89 & 28267 & 38 & 7 \\
\hline 19 & $M B P$ & myelin basic protein & gi|4454311 & 0.27 & 5.37 & 1.42 & 144 & 10.9 & 14184 & 42 & 8 \\
\hline
\end{tabular}




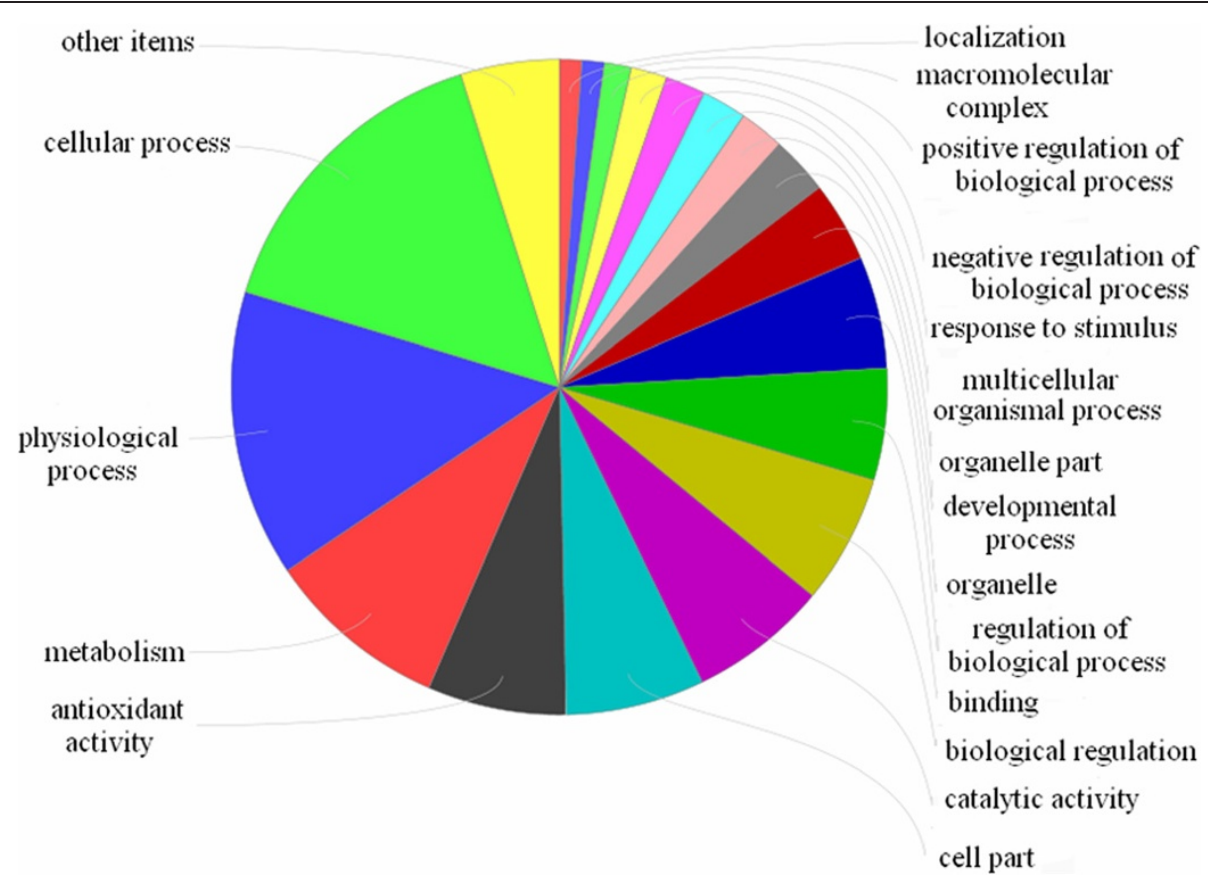

Figure 4 Ontology of differentially expressed proteins.

long-term memory consolidation in the hippocampus $[34,35]$, was involved in the analgesic effect of EA interventions. In rats with neuropathic pain, Xing et al. [36] demonstrated that EA treatment had a regulatory effect on long-term synaptic plasticity in the spinal dorsal horn. Experimental studies have demonstrated that under pain condition, changes in hippocampal synaptic plasticity are accompanied by changes in learning, memory, and adaptive processes. Interestingly, recent studies have independently shown hippocampal abnormalities in animal models of chronic pain including short-term recognition memory [37], long-term potentiation deficits, abnormal cytokine expression, and impaired enrichedenvironment neurogenesis [38]. Therefore, Changes of STIP1 following EA may suggest a direct link between information storage and the analgesic effect of EA.

The functional changes in the hippocampus were accompanied by changes of protein expression, particularly those proteins involving amino acid metabolism. For example, we found that expression of 3-mercaptopyruvate sulfurtransferase (MPST), aspartate aminotransferase 1 (GOT1), and lactate dehydrogenase B $(L D H B)$, which are involved in cysteine metabolism, was decreased after CCI. Among them, GOT1 is especially important as it also plays a key role in glutamate metabolism. It has been well established that under pain condition, glutamate level in the central never system was increased rapidly, so the decrease of GOT1 protein level following CCI suggests a shift in the equilibrium of GOT1 towards glutamate. Our results demonstrated that EA can apparently reverse the decrease of GOT1. This may be a critical mechanism of analgesic effect of EA. Chronic pain is also a type of chronic stress. Under chronic stress condition, significant decreases in hippocampal synaptic density and surface density have been reported [38] Remodeling of the synaptic compartments involves a variety of physiological processes, including enhanced translational activity and related protein synthesis. In the nervous system, neuronal activity is strongly correlated with the levels of amino acid metabolism, and a substantial amount of amino acids are required for changes in protein expression and production of cellular defense mechanisms. Many forms of long-lasting behavioral and synaptic plasticity also require the synthesis of new proteins [39]. Thus, it is feasible that the regulatory activities of many cellular enzymes, especially those in amino acid metabolism found in the present study, can change after $\mathrm{CCI}$.

We also observed a decrease in the expression of valine, leucine, and isoleucine degradation related proteins, isovaleryl-CoA dehydrogenase (IVD), 3hydroxyisobutyrate dehydrogenase $(H I B A D H)$, and aldehyde dehydrogenase 2 family $(A L D H 2)$. Karpova et al. [40] reported that hippocampal synaptic activity related to induction of long-term potentiation (LTP) led to a rapid increase in the rate of protein synthesis as well as accelerated protein degradation. Therefore, our study may lend new support to the concept 


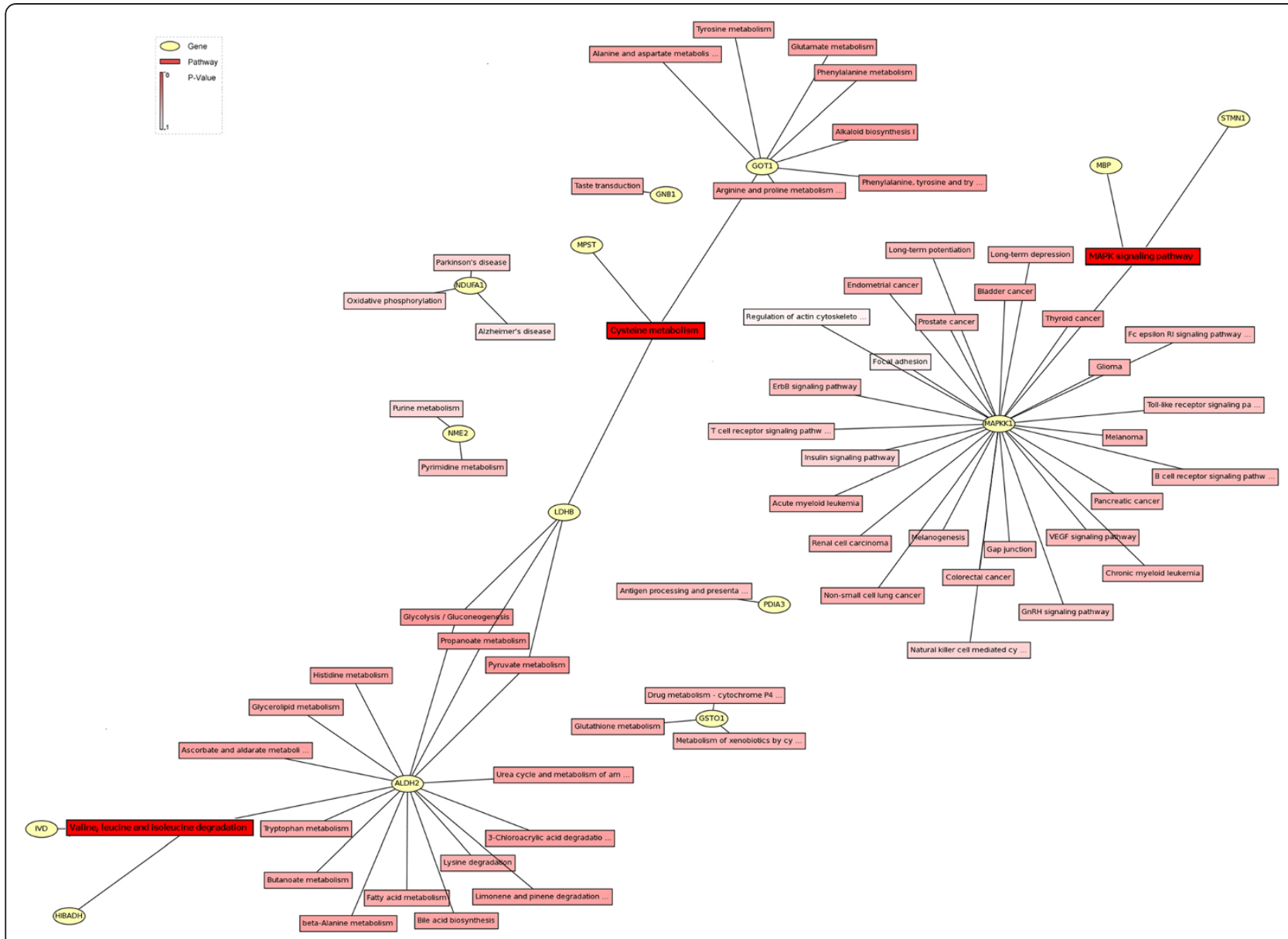

Figure 5 Protein networks of hippocampal differentially expressed proteins.

that complementary processes of enhanced protein synthesis and activity-dependent protein degradation is a mechanism underlying control of synaptic protein components $[41,42]$.

Glutathione (GSH), the major endogenous antioxidant produced by cells, has been shown to modulate the activity of N-methyl-D-aspartate receptors (NMDARs) via its reducing effects [43]. In the hippocampus, NMDARdependent LTP, a form of synaptic plasticity, is thought to represent a cellular model of memory. The NMDAR is the predominant glutamate receptor involved in hippocampal synaptic plasticity, and is critical for LTP, memory, and learning. Cysteine, a precursor for the formation of glutathione, reverses the L-type calcium channel-dependent LTP seen in the aged animals to NMDAR-dependent LTP [44]. Thus as such, modulating cysteine levels in the hippocampus by acupuncture stimulation may be a therapeutic strategy for treatment of impairments in plasticity and synaptic transmission function in CCI rats.

In response to stress or nerve injury, intracellular pathways that are normally inactive under steady-state condition are activated, while some of the normal pathways may be inhibited or bypassed. In a mouse model of pain induced by subcutaneous injection of formalin, Seo et al. [45] reported that intrathecal and intraperitoneal injection of glutamate or acetic acid resulted in up-regulation of hippocampal phosphorylated $\mathrm{Ca}^{2+} /$ calmodulin-dependent protein kinase II alpha or phosphorylated extracellular signal-regulated protein expression. In repeated stress stimulation-induced depression rats, EA also increased the number of $\mathrm{p}$-CREB-positive neurons in the hippocampus and restored hippocampal BDNF mRNA expression induced by immobilization stress [46]. These data suggest a role of EA in regulating cellular signal transduction in the hippocampus. We also found evidence of activation of MAPK signal transduction pathway proteins, mitogenactivated protein kinase kinase 1 (MAPKK1), stathmin 1 (STMN1), and myelin basic protein $(M B P)$ following EA $[47,48]$. The MAPKs are highly conserved across all eukaryotes, and their roles extend beyond the cytoplasm to the nucleus, where they can directly modulate gene transcription. The MAPK signal transduction pathway is also an important signaling event for the induction of 


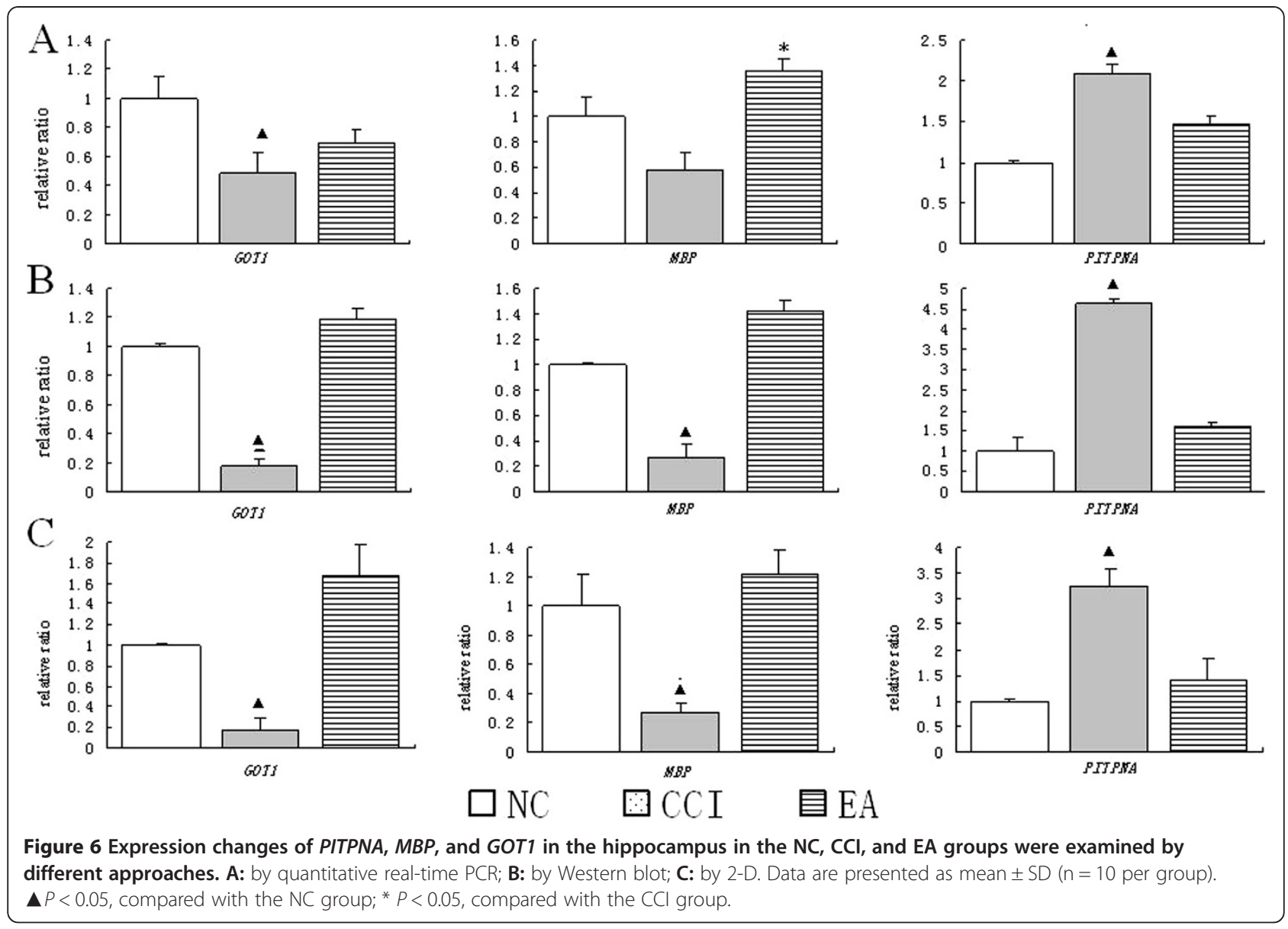

hippocampal LTP. Activation of this pathway is necessary for both the transcriptional and translational events underlying long-term memory formation in the hippocampus.

In the nervous system, nerve injury and stress condition can cause oxidative damage to the cytoskeleton and membrane structures. In addition, significant energy production is required for protein expression and cellular defense mechanisms. This is supported by the increased expression of proteins involving antioxidative processes, neuronal integrity, and glycolysis/gluconeogenesis observed in the present study.

The goal of our study was to examine for proteins involved in the analgesic effect of EA. Although there are few comparable studies, using 2-DE-based proteomics, Sung et al. [49] reported differential changes in 36 hypothalamic proteins in a model of rat-tail neuropathic pain, which were all restored to control levels following EA of ST36. Similar to our results, twenty-one of these proteins are involved in biological processes including enzyme metabolism and signal transduction, suggesting common mechanisms of EA-induced analgesia.
The expression of three differential proteins (PITPNA, $G O T 1$, and $M B P$ ) was further examined using quantitative real-time PCR and Western blot. Although changes in PITPNA and MBP mRNA were similar to that for 2-DE, there was no change in GOT1 mRNA. It is likely that this relates to mRNA-independent posttranslational modification, trafficking, and degradation, as a large number of modification sites and domains exist in GOT1.

\section{Conclusions}

Taken together, these results demonstrated that repeated EA at ST36 and GB34 produced an analgesic effect against CCI-induced neuropathic pain in rats. A total of 19 differential proteins were found to be involved in this process. Functional analysis showed that EA-mediated neuro-protection may be due to, at least in part, to the normalization of the altered expression of several proteins implicated in cysteine metabolism, valine, leucine, and isoleucine degradation, and MAPK signaling. Further studies are required to examine changes in these proteins over the course of EA treatment and to define their specific functions in regulating the analgesic effect of EA. 


\section{Abbreviations}

CCl: Chronic constrictive injury; EA: Electroacupuncture; NC: Normal control; 2-DE: Two-dimensional gel electrophoresis; MALDI-TOF MS: Matrix-assisted laser desorption/ionization time of flight mass spectrometry; PWL: Paw withdrawal latency; PWLD: Difference value of PWL; IEF: First-dimensional isoelectric focusing; MW: Molecular weight; pl: Isoelectric point; MAPK: Mitogenactivated protein kinase.

\section{Competing interests}

The authors declared that they have no competing interests.

\section{Authors' contributions}

YHG and JLL conceived this study and wrote the manuscript. YHG, SPC, JYW and LNQ carried out the experiment. FYM executed statistical analysis. QLX assisted in matrix-assisted laser desorption/ionization time-of-flight mass spectrometry detection. All authors read and approved the final manuscript.

\section{Acknowledgements}

This study was jointly supported by the National Nature Science Foundation (90709031, 81102647) and the Special Project of Chinese Medicine (973) of the National Basic Research Program of China (2007CB512505).

Received: 20 September 2012 Accepted: 27 November 2012 Published: 2 December 2012

\section{References}

1. Deyo RA, Mirza SK, Martin BI: Back pain prevalence and visit rates: estimates from U.S. national surveys, 2002. Spine (Phila Pa 1976) 2006, 31(23):2724-2727.

2. Berman BM, Langevin HM, Witt CM, Dubner R: Acupuncture for chronic low back pain. N Engl J Med 2010, 363(5):454-461.

3. Hart LG, Deyo RA, Cherkin DC: Physician office visits for low back pain. Frequency, clinical evaluation, and treatment patterns from a U.S. national survey. Spine (Phila Pa 1976) 1995, 20(1):11-19.

4. Leibing E, Leonhardt U, Koster G, Goerlitz A, Rosenfeldt JA, Hilgers R, Ramadori G: Acupuncture treatment of chronic low-back pain - a randomized, blinded, placebo-controlled trial with 9-month follow-up. Pain 2002, 96(1-2):189-196.

5. Carlsson CP, Sjolund BH: Acupuncture for chronic low back pain: a randomized placebo-controlled study with long-term follow-up. Clin J Pain 2001, 17(4):296-305.

6. Shen YF, Goddard G: The short-term effects of acupuncture on myofascial pain patients after clenching. Pain Pract 2007, 7(3):256-264.

7. Kim HN, Park JH, Kim SK, Sun B, Koo S, Choi SM, Bae H, Min Bl: Electroacupuncture potentiates the antiallodynic effect of intrathecal neostigmine in a rat model of neuropathic pain. J Physiol Sci 2008 , 58(5):357-360.

8. Yim YK, Lee H, Hong KE, Kim YI, Lee BR, Son CG, Kim JE: Electroacupuncture at acupoint ST36 reduces inflammation and regulates immune activity in collagen-induced arthritic mice. Evid Based Complement Alternat Med 2007, 4(1):51-57.

9. Bai L, Tian J, Zhong C, Xue T, You Y, Liu Z, Chen P, Gong Q, Ai L, Qin W, et al: Acupuncture modulates temporal neural responses in wide brain networks: evidence from fMRI study. Mol Pain 2010, 6:73.

10. Guo ZL, Longhurst JC: Expression of c-Fos in arcuate nucleus induced by electroacupuncture: relations to neurons containing opioids and glutamate. Brain Res 2007, 1166:65-76.

11. Zeng F, Song WZ, Liu XG, Xie HJ, Tang Y, Shan BC, Liu ZH, Yu SG, Liang FR: Brain areas involved in acupuncture treatment on functional dyspepsia patients: a PET-CT study. Neurosci Lett 2009, 456(1):6-10.

12. Bingel U, Quante M, Knab R, Bromm B, Weiller C, Buchel C: Subcortical structures involved in pain processing: evidence from single-trial fMRI. Pain 2002, 99(1-2):313-321.

13. Zhang JH, Li J, Cao XD, Feng XY: Can electroacupuncture affect the sympathetic activity, estimated by skin temperature measurement? a functional MRI study on the effect of needling at GB 34 and GB 39 on patients with pain in the lower extremity. Acupunct Electrother Res 2009, 34(3-4):151-164.

14. Dhond RP, Yeh C, Park K, Kettner N, Napadow V: Acupuncture modulates resting state connectivity in default and sensorimotor brain networks. Pain 2008, 136(3):407-418.
15. Xu QL, Liu T, Chen SP, Gao YH, Wang JY, Qiao LN, Liu JL: The cumulative analgesic effect of repeated electroacupuncture involves synaptic remodeling in the hippocampal CA3 region. Neu Reg Res 2012, 7(18):1378-1385.

16. Kodama D, Ono H, Tanabe M: Altered hippocampal long-term potentiation after peripheral nerve injury in mice. Eur J Pharmacol 2007, 574(2-3):127-132.

17. Ulrich-Lai YM, Xie W, Meij JT, Dolgas CM, Yu L, Herman JP: Limbic and HPA axis function in an animal model of chronic neuropathic pain. Physiol Behav 2006, 88(1-2):67-76.

18. Leong MS, Solvason HB: Case report: limbic system activation by intravenous lidocaine in a patient with a complex regional pain syndrome and major depression. Pain Med 2000, 1(4):358-361.

19. Emad Y, Ragab Y, Zeinhom F, El-Khouly G, Abou-Zeid A, Rasker JJ: Hippocampus dysfunction may explain symptoms of fibromyalgia syndrome. A study with single-voxel magnetic resonance spectroscopy. J Rheumatol 2008, 35(7):1371-1377.

20. Chou CW, Wong GT, Lim G, McCabe MF, Wang S, Irwin MG, Mao J: Peripheral nerve injury alters the expression of NF-kappaB in the rat's hippocampus. Brain Res 2011, 1378:66-71

21. Hobson SA, Bacon A, Elliot-Hunt CR, Holmes FE, Kerr NC, Pope R, Vanderplank P, Wynick D: Galanin acts as a trophic factor to the central and peripheral nervous systems. EXS 2011, 102:25-38.

22. Hu Y, Yang J, Wang Y, Li W: Amitriptyline rather than lornoxicam ameliorates neuropathic pain-induced deficits in abilities of spatial learning and memory. Eur J Anaesthesiol 2009, 27(2):162-168.

23. Wang X, Zhang Y, Kong L, Xie Z, Lin Z, Guo N, Strong JA, Meij JT, Zhao Z, Jing $N$, et al: RSEP1 is a novel gene with functional involvement in neuropathic pain behaviour. Eur J Neurosci 2005, 22(5):1090-1096.

24. Jungblut PR, Schluter H: Towards the analysis of protein species: an overview about strategies and methods. Amino Acids 2011, 41(2):219-222.

25. Bennett GJ, Xie YK: A peripheral mononeuropathy in rat that produces disorders of pain sensation like those seen in man. Pain 1988, 33(1):87-107.

26. Liu JL, Chen SP, Gao YH, Meng FY, Wang SB, Wang JY: Effects of repeated electroacupuncture on beta-endorphin and adrencorticotropic hormone levels in the hypothalamus and pituitary in rats with chronic pain and ovariectomy. Chin J Integr Med 2010, 16(4):315-323.

27. Cohen M, Parker S, Taylor D, de Smit V, Ben-Meir M, Cameron P, Xue C: Acupuncture as analgesia for low back pain, ankle sprain and migraine in emergency departments: study protocol for a randomized controlled trial. Trials 2012, 12:241.

28. Chernyak GV, Sessler DI: Perioperative acupuncture and related techniques. Anesthesiology 2005, 102(5):1031-1049. quiz 1077-1038.

29. Junker H, Venz S, Zimmermann U, Thiele A, Scharf C, Walther R: Stage-related alterations in renal cell carcinoma-comprehensive quantitative analysis by 2D-DIGE and protein network analysis. PLoS One 2011, 6(7):e21867.

30. Yuan J, Zhu L, Liu X, Li T, Zhang Y, Ying T, Wang B, Wang J, Dong H, Feng E, et al: A proteome reference map and proteomic analysis of bifidobacterium longum NCC2705. Mol Cell Proteomics 2006, 5(6):1105-1118.

31. Gorg A, Weiss W, Dunn MJ: Current two-dimensional electrophoresis technology for proteomics. Proteomics 2004, 4(12):3665-3685.

32. Gao YH, Chen SP, Wang JY, Qiao LN, Xu QL, Liu JL: Effects of electroacupuncture at different acupoints on the pain behavior and NMDA receptor $2 \mathrm{~B}$ subunit mRNA and protein expression and phosphorylation level in the cervical spinal cord in rats with thyroid regional pain. Zhen Ci Yan Jiu 2009, 34(6):376-382.

33. Chen MR, Wang P, Cheng G, Guo X, Wei GW, Xu-hui C: Effect of warming needle moxibustion on pain threshold in the patient of sciatica. Zhongquo Zhen Jiu 2005, 25(12):831-833.

34. Coitinho AS, Lopes MH, Hajj GN, Rossato Jl, Freitas AR, Castro CC, Cammarota M, Brentani RR, Izquierdo I, Martins VR: Short-term memory formation and long-term memory consolidation are enhanced by cellular prion association to stress-inducible protein 1. Neurobiol Dis 2007, 26(1):282-290.

35. del Rey A, Yau HJ, Randolf A, Centeno MV, Wildmann J, Martina M, Besedovsky HO, Apkarian AV: Chronic neuropathic pain-like behavior correlates with IL-1 beta expression and disrupts cytokine interactions in the hippocampus. Pain 2011, 152(12):2827-2835.

36. Xing GG, Liu FY, Qu XX, Han JS, Wan Y: Long-term synaptic plasticity in the spinal dorsal horn and its modulation by electroacupuncture in rats with neuropathic pain. Exp Neurol 2007, 208(2):323-332. 
37. Ren WJ, Liu Y, Zhou LJ, Li W, Zhong Y, Pang RP, Xin WJ, Wei XH, Wang J, Zhu $H Q$, et al: Peripheral nerve injury leads to working memory deficits and dysfunction of the hippocampus by upregulation of TNF-alpha in rodents. Neuropsychopharmacology 2011, 36(5):979-992.

38. Mutso AA, Radzicki D, Baliki MN, Huang L, Banisadr G, Centeno MV, Radulovic J, Martina M, Miller RJ, Apkarian AV: Abnormalities in hippocampal functioning with persistent pain. J Neurosci 2012, 32(17):5747-5756.

39. Tang SJ, Reis G, Kang H, Gingras AC, Sonenberg N, Schuman EM: A rapamycin-sensitive signaling pathway contributes to long-term synaptic plasticity in the hippocampus. Proc Natl Acad Sci U S A 2002, 99(1):467-472.

40. Karpova A, Mikhaylova M, Thomas U, Knopfel T, Behnisch T: Involvement of protein synthesis and degradation in long-term potentiation of Schaffer collateral CA1 synapses. J Neurosci 2006, 26(18):4949-4955.

41. Colledge M, Snyder EM, Crozier RA, Soderling JA, Jin Y, Langeberg LK, Lu H, Bear MF, Scott JD: Ubiquitination regulates PSD-95 degradation and AMPA receptor surface expression. Neuron 2003, 40(3):595-607.

42. Hegde AN: Ubiquitin-proteasome-mediated local protein degradation and synaptic plasticity. Prog Neurobiol 2004, 73(5):311-357.

43. Robillard JM, Gordon GR, Choi HB, Christie BR, MacVicar BA: Glutathione restores the mechanism of synaptic plasticity in aged mice to that of the adult. PLoS One 2011, 6(5):e20676.

44. Nakazawa K, Quirk MC, Chitwood RA, Watanabe M, Yeckel MF, Sun LD, Kato A, Carr CA, Johnston D, Wilson MA, et al: Requirement for hippocampal CA3 NMDA receptors in associative memory recall. Science 2002, 297(5579):211-218.

45. Seo YJ, Kwon MS, Choi HW, Choi SM, Kim YW, Lee JK, Park SH, Jung JS, Suh HW: Differential expression of phosphorylated Ca2+/calmodulindependent protein kinase II and phosphorylated extracellular signalregulated protein in the mouse hippocampus induced by various nociceptive stimuli. Neuroscience 2008, 156(3):436-449.

46. Yun SJ, Park HJ, Yeom MJ, Hahm DH, Lee HJ, Lee EH: Effect of electroacupuncture on the stress-induced changes in brain-derived neurotrophic factor expression in rat hippocampus. Neurosci Lett 2002, 318(2):85-88.

47. Wang SJ, Yang HY, Xu GS: Acupuncture alleviates colorectal hypersensitivity and correlates with the regulatory mechanism of TrpV1 and p-ERK. Evid Based Complement Alternat Med 2012, 2012:483123.

48. Lai X, Wang J, Nabar NR, Pan S, Tang C, Huang Y, Hao M, Yang Z, Ma C, Zhang J, et al: Proteomic response to acupuncture treatment in spontaneously hypertensive rats. PLoS One 2012, 7(9):e44216.

49. Sung HJ, Kim YS, Kim IS, Jang SW, Kim YR, Na DS, Han KH, Hwang BG, Park $D S$, Ko J: Proteomic analysis of differential protein expression in neuropathic pain and electroacupuncture treatment models. Proteomics 2004, 4(9):2805-2813.

doi:10.1186/1472-6882-12-241

Cite this article as: Gao et al:: Differential proteomics analysis of the analgesic effect of electroacupuncture intervention in the hippocampus following neuropathic pain in rats. BMC Complementary and Alternative Medicine 2012 12:241.

\section{Submit your next manuscript to BioMed Central and take full advantage of:}

- Convenient online submission

- Thorough peer review

- No space constraints or color figure charges

- Immediate publication on acceptance

- Inclusion in PubMed, CAS, Scopus and Google Scholar

- Research which is freely available for redistribution 